\title{
PROTOTYPE PENYIRAM TANAMAN HIAS DENGAN SOIL MOISTURE SENSOR BERBASIS ARDUINO
}

\author{
Ridarmin $^{1}$, Zulizha Pandu Pertiwi ${ }^{2}$ \\ Sekolah Tinggi Manajemen Informatika dan Komputer (STMIK) Dumai \\ Jl. Utama Karya Bukit Batrem, Dumai, Kode Pos : 28811 \\ ridamin@yahoo.co.id
}

\begin{abstract}
ABSTRAK
Tanaman merupakan tumbuhan yang dibudidayakan agar dapat diambil manfaatnya. Budidaya tanaman sendiri pada dasarnya dapat menjadi peluang usaha yang menjanjikan. Mulai dari budidaya tanaman hias, sayur mayur dan lain sebagainya. Tetapi saat ini produksi tanaman hias masih banyak yang belum menghasilkan hasil yang maksimal, dikarenakan masyarakat masih menggunakan teknologi manual dalam sistem pertanian yang digunakan. Tujuan dilakukan penelitian ini adalah merancang sebuah alat penyiraman tanaman hias otomatis untuk mengatasi masalah dalam penyiraman tanaman hias yang masin dilakukan secara manual dan sebagai bahan pembelajaran. Prototype ini menggunakan Arduino Uno sebagai pengontrol utama, sensor kelembaban tanah digunakan untuk membaca kadar kelembaban tanah dan digunakan sebagai saklar untuk menghidupkan pompa penyiram. Dengan adanya alat penyiram otomatis ini, sensor kelembaban tanah akan membaca kelembaban tanah apakah tanah dalam keadaan kering apa sudah dalam keadaan basah. Ketika tanah dalam keadaan kering alat penyiram akan menyiram sampai tanah menjadi basah dan ketika sudah basah mesin akan mati secara otomatis.
\end{abstract}

Kata kunci : prototype, penyiram tanaman Arduino UNO, Sensor kelembaban tanah, Tanaman Hias.

\section{Pendahuluan}

\subsection{Latar Belakang}

Tanah merupakan salah satu media yang digunakan sebagai media hidup dari berbagai macam tumbuhan. Tanaman memerlukan air untuk dapat tumbuh secara optimal. Untuk itulah kondisi kelembaban tanah harus dijaga pada suatu keadaan tertentu yang sesuai dengan kebutuhan tanaman. Kelembaban tanah sering menjadi faktor penentu dari keberhasilan tumbuhnya tanaman disamping faktor lain seperti kandungan mineral tanah. Di sisi lain, keterbatasan indera manusia menyebabkan kondisi kadar air tanah untuk dapat diketahui secara tepat. Kekurangan kadar air atau kelebihan kadar air dapat mengakibatkan tanaman tidak dapat tumbuh dengan baik. Oleh karena itu, diperlukan suatu sistem yang bekerja secara otomatis dan cerdas untuk melakukan penyiraman tanaman. Sistem ini akan menjaga kadar air pada tanah yang sesuai dengan kebutuhan tanaman. Kondisi kadar air tanah diperoleh dari sensor kelembaban tanah dan dipengaruhi juga oleh suhu udara.

Air merupakan senyawa yang sangat penting bagi tumbuhan. Air berfungsi sebagai media reaksi kimia dalam sel. Selain itu, air menunjang proses fotosintesis dan menjaga kelembaban. Kandungan air yang terdapat dalam tanah berfungsi sebagai pelarut unsur hara sehingga unsur hara mudah diserap bagi tanaman. Unsur hara adalah sumber nutrisi atau makanan yang dibutuhkan tanaman baik itu unsur hara yang tersedia didalam (organik) maupun yang sengaja ditambahkan. Selain itu, air memelihara suhu tanah yang berperan dalam proses pertumbuhan.

Dikarenakan masih kurangnya teknologi modern yang dapat meningkatkan produktifitas hasil tanaman, teknologi yang dipakai masyarakat saat ini kebanyakan masih menggunakan teknologi manual, sehingga dengan cara manual dimungkinkan saat penyiraman membuat tanaman itu mati karena kelebihan atau kekurangan air. Kekurangan air bagi tanaman dapat menyebabkan aktivitas proses dan fisiologis tanaman terhambat bahkan tidak akan berjalan, tanaman yang kekurangan air akan menyebabkan tanaman layu karena jaringan-jaringan tanaman tidak lagi berfungsi dengan baik. Sedangkan kelebihan air pada tanaman akan meyebabkan permukaan tanah tempat tanaman hidup akan lembab, keadaan lembab tersebut akan memunculkan mikroorganisme jamur yang akan mengakibatkan tumbuhnya penyakit bagi tanaman. Untuk meningkatkan hasil tanaman 
yang baik dibutuhkan alat penyiram secara otomatis. Oleh karena itu tujuan dilakukan penelitian ini adalah merancang sebuah alat penyiraman tanaman otomatis dengan menggunakan Soil moisture sensor (sensor kelembaban tanah) untuk mengatasi masalah kekurangan dan kelebihan air pada tanah. Soil moisture sensor akan membaca kelembaban tanah apakah tanah dalam keadaan kering apa sudah dalam keadaan basah. Ketika tanah dalam keadaan kering alat penyiram akan menyiram sampai tanah menjadi basah dan ketika sudah basah mesin akan mati dengan sendirinya.

Pekembangan IPTEK khususnya komputer sudah demikian majunya merambah setiap bidang kehidupan. Hampir semua aktifitas kegiatan manusia menggunakan teknologi modern. Banyaknya penggunaan dan pemanfatan teknologi komputer adalah karena komputer mampu melakukan pekerjaan yang berulang secara terus- menerus, tanpa mengenal waktu, hal ini dapat dimanfaatkan untuk membantu manusia mengerjakan pekerjaan yang rutinitas. Pemanfaatan teknologi modern pada bidang produksi tanaman hias diharapkan dapat meningkatkan hasil yang baik pada tanaman hias tersebut.

\subsection{Tujuan Penelitian}

Tujuan dilakukan penelitian ini adalah merancang sebuah alat penyiraman tanaman hias otomatis untuk mengatasi masalah dalam penyiraman pada tanaman dan sebagai bahan pembelajaran.

\subsection{Tinjauan pustaka}

\section{A. Tanah}

Tanah mempunyai arti penting bagi tanaman. Dalam mendukung kehidupan tanaman, tanah memiliki fungsi untuk memberikan unsur hara dan sebagai media perakaran, menyediakan air dan sebagai tempat penampungan air, menyediakan udara untuk respirasi akar dan sebagai tempat bertumpunya tanaman. Tanah yang dikehendaki tanaman adalah tanah yang subur. Tanah yang subur adalah tanah yang mampu untuk menyediakan unsur hara yang cocok, dalam jumlah yang cukup serta dalam keseimbangan yang tepat dan lingkungan yang sesuai untuk pertumbuhan suatu spesies tanaman ${ }^{1}$.

\section{B. Tanaman Hias}

Tanaman Hias adalah segala jenis tanaman yang memiliki nilai hias (bunga, batang, tajuk, cabang, daun,cakar, aroma dsb) yang menimbulkan kesan indah (artistic) atau kesan seni. Tanaman hias terdiri dari tanama hias pot, tanaman hias potong, tanaman hias daun dan tanaman hias lansekap/taman. Manfaat dan kegunaan tanaman hias memiliki 3 aspek kepentingan yaitu : Dinas Pertanian Tanaman Pangan (Pengembangan Tanaman Hias di Sumatera Barat, 2014:h.1).

\section{Pengertian Sistem}

Sistem adalah kumpulan dari elemenelemen yang berinteraksi untuk mencapai suatu tujuan tertentu (Jogiyanto 2009:h.1). Pendekatan sistem yang merupakan kumpulan dari elemen-elemen atau komponen-komponen atau subsistem-subsistem merupakan definisi yang lebih luas. Defenisi ini lebih banyak diterima, karena kenyataannya suatu sistem data terdiri dari beberapa subsistem atau sistem-sistem bagian (Jogiyanto, 2009:h.2).

Suatu sistem adalah jaringan kerja dari prosedur-prosedur yang saling berhubungan, berkumpul bersama-sama untuk melakukan suatu kegiatan atau menyelesaikan suatu sasaran tertentu. Suatu sistem yang baik harus mempunyai tujuan dan sasaran yang tepat karena hal ini akan sangat menentukan dalam mendefenisikan masukan yang dibutuhkan sistem dan juga keluaran yang dihasilkan (Kristanto. 2008:h.1).

\section{Pengertian Informasi}

Informasi merupakan kumpulan data yang diolah menjadi bentuk yang lebih berguna dan lebih berarti bagi yang menerima. Tanpa suatu informasi, suatu sistem tidak akan berjalan dengan lancer dan akhirnya mati. Sumber informasi adalah data. Data menggambarkan suatu kejadian yang sedang terjadi, dimana data tersebut akan diolah dan diterapkan dalam sistem menjadi input yang berguna dalam suatu sistem (Kristanto. 2008:h.7).

\section{E. Arduino}

Arduino Uno adalah salah satu produk nerlabel Arduino yang sebenarnya adalah suatu papan elektronik yang mengandung mikrokontroler ATmega328 (Sebuah keeping yang secara fungsional bertindak seperti sebuah komputer). Peranti ini dapat dimanfaatkan untuk mewujudkan rangkaian elektronik dari yang sederhana hingga yang kompleks. Arduino Uno mengandung mikroprosesor (berupa Armel AVR) dan dilengkapi dengan oscillator 
I N F ORM A T I N

Jurnal Informatika, Manajemen dan Komputer, Vol. 10 No. 1, Mei 2018

eISSN : 2580-3042

pISSN : 1979-0694

$16 \mathrm{MHz}$ (yang memungkinkan operasi berbasis waktu dilaksanakan dengan tepat), dan regulator (pembangkit tegangan) 5 volt. (Afrie Setiawan. 2010)

\section{F. Soil moisture sensor}

Soil moisture sensor adalah sensor kelembaban yang dapat mendeteksi kelembaban dalam tanah. Sensor ini sangat sederhana, tetapi ideal untuk memantau taman kota, atau tingkat air pada tanaman pekarangan. Sensor ini terdiri dua probe untuk melewatkan arus melalui tanah, kemudian membaca resistansinya untuk mendapatkan nilai tingkat kelembaban. Semakin banyak air membuat tanah lebih mudah menghantarkan listrik (resistansi kecil), sedangkan tanah yang kering sangat sulit menghantarkan listrik (resistansi besar). Sensor ini sangat membantu untuk mengingatkan tingkat kelembaban pada tanaman atau memantau kelembaban tanah. ${ }^{2}$

\section{Metode Penelitian}

\subsection{Rancangan Penelitian}

Dalam penelitian ini metode yang digunakan meliputi perancangan rangkaian elektrik, sistematis, agar diperoleh data dan informasi yang akurat.
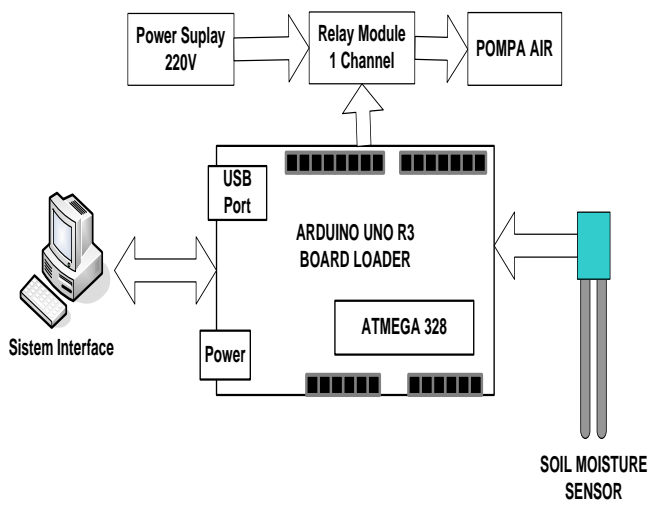

Gambar 1. Block Diagram Sistem Penyiraman Tanaman Hias Secara Otomatis

\section{Hasil dan Pembahasan}

\section{A. Context Diagram}

Sistem yang sedang berjalan pada perancangan sistem penyiraman tanaman otomatis menggunakan Soil moisture sensor dengan arduino dapat dilihat pada gambar Context Diagram sebagai berikut :

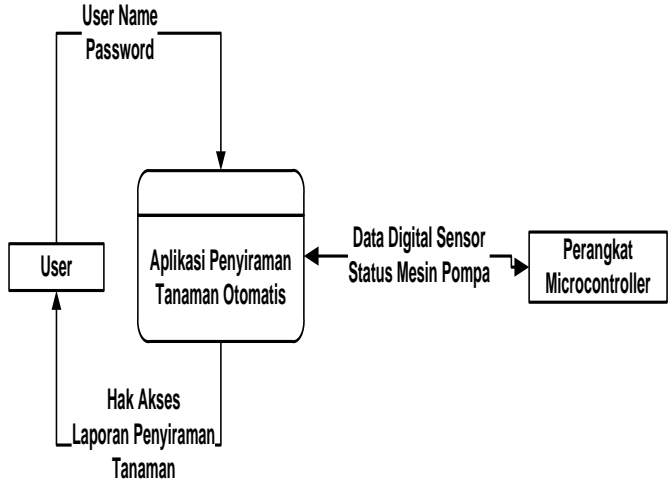

Gambar 2. Context Diagram Penyiraman

Tanaman Hias Secara Otomatis

\section{B. Data Flow Diagram}

DFD menunjukkan hubungan antara data pada sistem dan proses pada sistem. Sistem yang sedang berjalan pada perancangan sistem penyiraman tanaman otomatis menggunakan Soil moisture sensor dengan arduino dapat dilihat pada gambar DFD sebagai berikut :

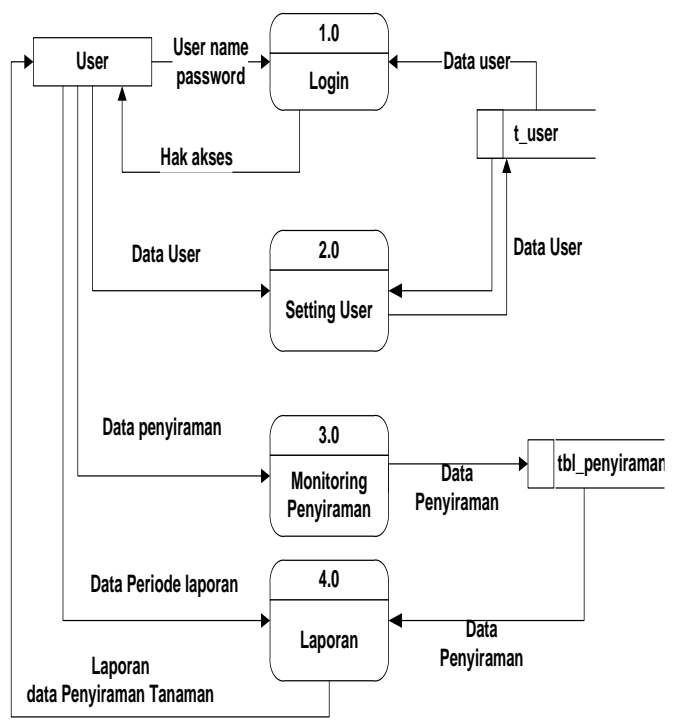

Gambar 3. Data Flow Diagram Penyiraman Tanaman Hias Secara Otomatis 
I N F ORM A T I N

Jurnal Informatika, Manajemen dan Komputer, Vol. 10 No. 1, Mei 2018

eISSN : 2580-3042

pISSN : 1979-0694

\section{Flowchart Rangkaian Pengendali}

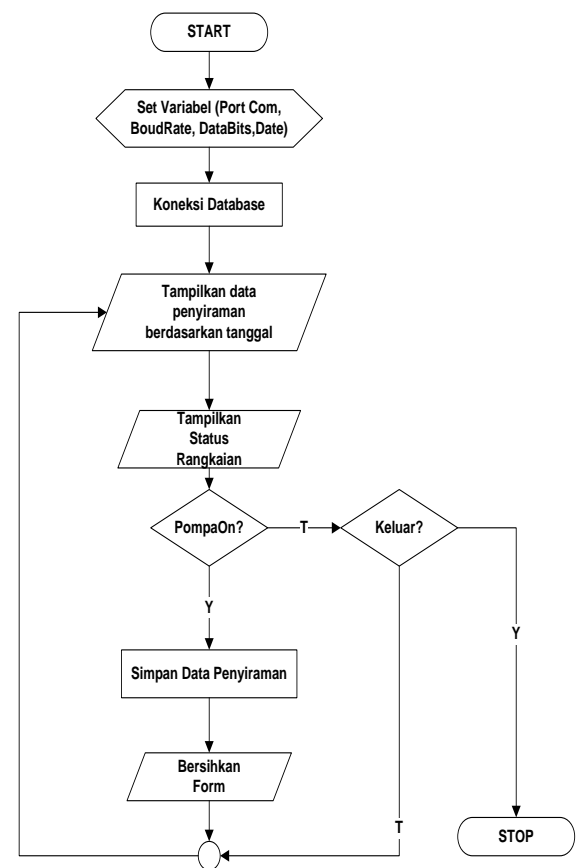

Gambar 4. Flowchart Rangkaian Pengendali Penyiraman Tanaman Hias Secara Otomatis

\section{Implementasi Sistem}

Langkah-langkah dan cara dalam melakukan implementasi sistem yang terdiri dari layout program, aplikasi, petunjuk pengoperasian program, pembuatan program. Tahap implementasi merupakan tahap meletakkan sistem agar dalam proses pengolahan data serta informasi pada perekaman data selalu siap di operasikan. Tahap ini juga termasuk kegiatan menulis kode program.

\section{Login}

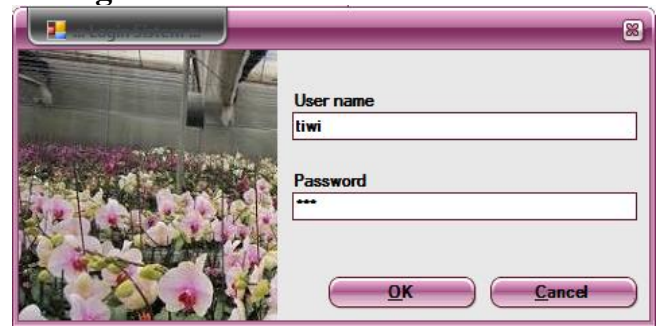

Gambar 5. Tampilan Login

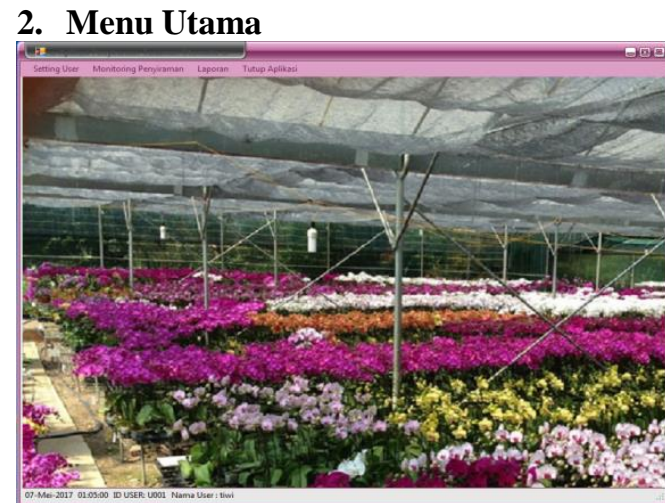

Gambar 6. Tampilan Menu Utama

\section{Setting User}

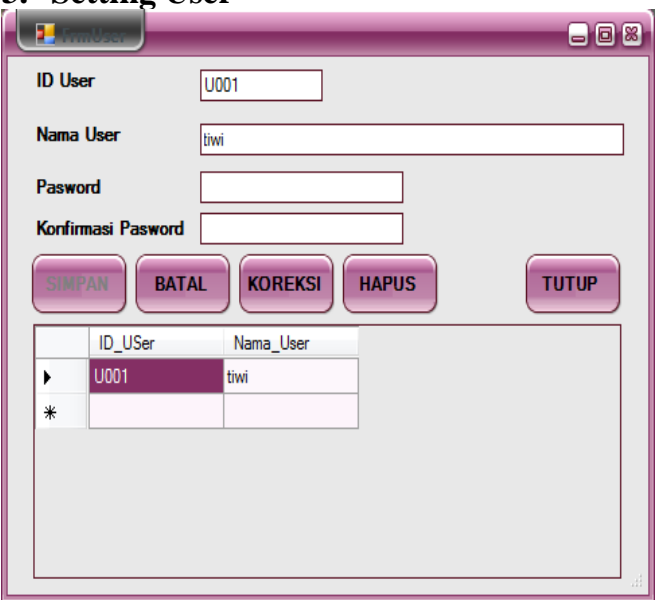

Gambar 7. Tampilan Setting User

\section{Monitoring Penyiraman}

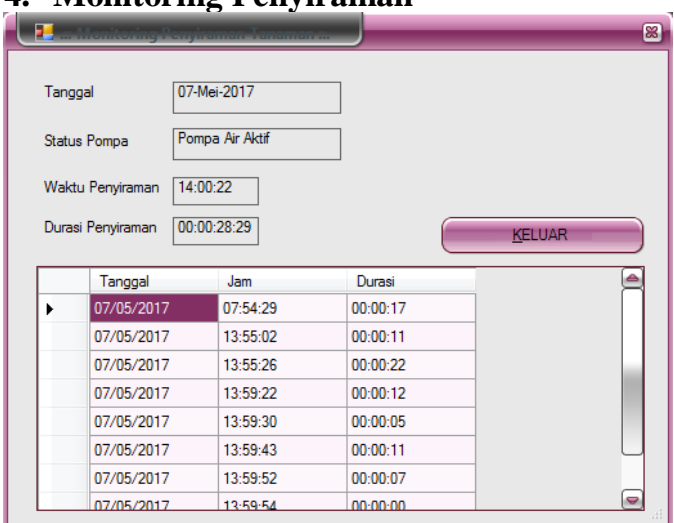

Gambar 8. Monitoring Penyiraman 
IN F ORM I T I H

Jurnal Informatika, Manajemen dan Komputer, Vol. 10 No. 1, Mei 2018

eISSN : 2580-3042

pISSN : 1979-0694

\section{Laporan}

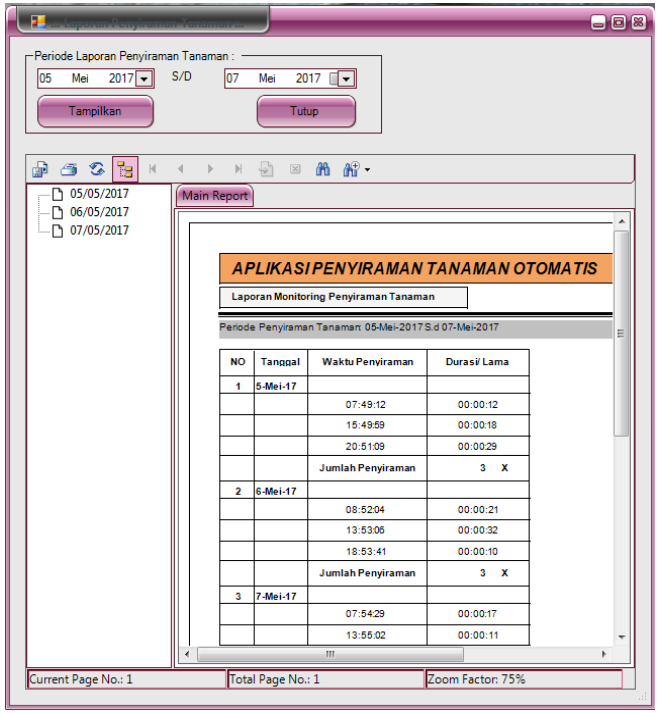

Gambar 9. Tampilan Laporan

\section{Pengujian Sistem}

APLIKASI PENYIRAMAN TANAMANOTOMATIS

Ladoran Monitorina Penviraman Tanaman

Periode Penyiraman Tanaman 05-Mei2017 S.d 07-Mei2017

\begin{tabular}{|c|c|c|c|}
\hline NO & Tanqqal & Waktu Penviraman & Durasil Lama \\
\hline \multirow[t]{5}{*}{1} & 5-Mei-17 & & \\
\hline & & $07: 49 \cdot 12$ & $00: 00: 12$ \\
\hline & & $15: 49: 59$ & $00: 00: 18$ \\
\hline & & $20: 51: 09$ & $00: 00: 29$ \\
\hline & & Jumlah Penviraman & $3 x$ \\
\hline \multirow[t]{5}{*}{2} & 6-Mei-17 & & \\
\hline & & $08: 5204$ & $00: 00: 21$ \\
\hline & & $13: 53: 06$ & $00: 00: 32$ \\
\hline & & $18: 53: 41$ & $00: 00: 10$ \\
\hline & & Jumlah Penviraman & $3 x$ \\
\hline \multirow[t]{12}{*}{3} & 7-Mei-17 & & \\
\hline & & $07: 54: 29$ & $00: 00: 17$ \\
\hline & & $13: 55: 02$ & $00: 00: 11$ \\
\hline & & $13: 55.26$ & $00: 00: 22$ \\
\hline & & $13: 59: 22$ & $00: 00: 12$ \\
\hline & & $13: 59: 30$ & $00: 0005$ \\
\hline & & $13: 59.43$ & $00: 00: 11$ \\
\hline & & $13: 59: 52$ & $00: 00: 07$ \\
\hline & & $13: 59.54$ & $00: 00: 00$ \\
\hline & & $14: 01: 02$ & $00: 01: 06$ \\
\hline & & $14: 01: 07$ & $00: 00: 03$ \\
\hline & & Jumlah Penviraman & $10 x$ \\
\hline
\end{tabular}

Gambar 10. Pengujian Sistem

\section{Simpulan}

Dari uraian dan pembahasan serta pengujian yang telah dilakukan, dapat diambil beberapa kesimpulan sebagai berikut :

1. Prototype ini dapat menyiram tanaman hias secara otomatis karena adanya sensor kelembaban tanah yang mampu mendeteksi kadar kelembaban tanah sehingga dapat mencegah terjadinya kekurangan dan kelebihan air pada tanah tanaman.

2. Soil moisture sensor berhasil di implementasikan sebagai input-an sehingga saat dioperasikan untuk dapat mendeteksi kelembaban tanah tanaman dengan baik.

3. Relay yang berfungsi sebagai saklar dapat berfungsi dengan baik dalam menjalankan pompa air sehingga tanaman dapat disiram tepat pada waktu yang dibutuhkan oleh tanaman sesuai dengan kelembaban tanah yang dibaca oleh sensor.

\section{Referensi}

1. Abdul Kadir. (2013). Panduan Praktis Mempelajari Aplikasi Mikrocontroller dan Pemogramannya Menggunakan Arduino. Yogyakarta: Andi

2. Afrie Setiawan. (2010) Mikrokontroler ATMEGA 8535 \& ATMEGA 16 Menggunakan BASCOM-AVR. Yogyakarta: Andi

3. Agus Andi Sulhan_Peranan Tanah Bagi Tanaman (Fakultas Pertanian, Universitas Udayana )

4. Andri Kristanto. (2008). Perancangan Sistem Informasi dan Aplikasi. Yogyakarta: Gava Media

5. Dinas Pertanian Tanaman Pangan. (2014). Pengembangan Tanaman Hias. Sumatera Barat: Dinas Pertanian Tanaman Pangan

6. HM, Jogiyanto. (2009). Sistem Teknologi Informasi. Yogyakarta: Andi 